\title{
Safety and Complications of Interventional Endoscopic Ultrasound
}

\author{
Monica Saumoy and Michel Kahaleh \\ Department of Gastroenterology, Weill Cornell Medical College, New York, NY, USA
}

Endoscopic ultrasound (EUS) has become an essential tool for the diagnostic and therapeutic intervention of gastrointestinal diseases. Beyond the drainage of fluid collections, it enables decompression of inaccessible bile and pancreatic ducts, the gallbladder, and the creation of anastomosis within the gastrointestinal tract using fully lumen-apposing stents. This review explored the safety and efficacy of these novel procedures and discussed the training pathway that is necessary to perform them efficiently and safely. Clin Endosc 2018;51:235-238

Key Words: Endosonography; Therapeutics; Pseudocyst; EUS-BD; EUS-GLB

\section{INTRODUCTION}

Historically, endoscopic ultrasound (EUS) has been a diagnostic procedure focused on the identification of key structures and the staging of gastrointestinal cancers. However, owing to technological advancements, EUS has expanded from diagnostic sampling into the field of therapeutic procedures. To perform these interventional techniques, an endoscopist must appreciate the added risk of using a transmural needle to puncture a sterile space via ultrasound guidance (as opposed to direct visualization). The increased risk of complications with interventional EUS procedures as compared with conventional endoscopy has been well documented. In addition, advanced therapeutic procedures can fail in up to $15 \%-30 \%$ of cases, especially in the hands of inexperienced surgeons. ${ }^{1}$ However, the current literature suggests that EUS-guided transmural interventions are safe, efficacious, have fewer

Received: May 19, 2017 Accepted: June 3, 2017

Correspondence: Michel Kahaleh

Department of Gastroenterology, Weill Cornell Medical College, 1305 York Avenue, 4th Floor, New York, NY 10021, USA

Tel: +1-646-962-4000, Fax: +1-646-962-0110, E-mail: mkahaleh@gmail.com ORCID: http://orcid.org/0000-0003-0836-6114

cc This is an Open Access article distributed under the terms of the Creative Commons Attribution Non-Commercial License (http://creativecommons.org/ licenses/by-nc/3.0) which permits unrestricted non-commercial use, distribution, and reproduction in any medium, provided the original work is properly cited. complications than percutaneous radiological interventions, and are less invasive compared to surgical procedures, when performed by expert endoscopists. ${ }^{2}$ Due to the increased complexity of advanced therapeutic procedures, additional endoscopic skills require a further 12-24 months of training to develop. ${ }^{3,4}$ EUS-related complications can be broadly categorized as bleeding, infection, or perforation, but can be more specifically described according to the particular interventional procedure. Interventional EUS procedures are also being continuously refined to make them safer and more efficient.

\section{PANCREATIC FLUID COLLECTIONS}

EUS-guided drainage procedures have now largely replaced the conventional surgical drainage of pancreatic fluid collections, with transenteric drainage as the preferred route. ${ }^{5}$ EUS helps to assess maturity of the fluid collection, assess wall thickness, and identify and avoid vascular strictures, as well as anticipate the presence of solid or other necrotic components within the cavity. Initially, conventional transmural drainage demonstrated a $72 \%$ technical success rate; however, the current technical success rate of EUS-guided drainage of pseudocysts or walled-off necrosis has increased to greater than $95 \%$. Moreover, lower complication rates have been facilitated by dedicated EUS-guided lumen-apposing metal stents, which 
prevent stent dislodgement from a collection that is not adherent to the stomach wall. ${ }^{6,7}$

Procedure-related complications rates range from $5 \%-18 \%{ }^{7-10}$ These procedure complications are typically secondary to perforation or bleeding. Complication rates can also vary based on the type of pancreatic fluid collection. Varadarajulu et al. demonstrated a 5\% complication rate with simple pseudocysts and a $16 \%$ complication rate from infected pseudocysts. ${ }^{11}$ Perforation-related complications can occur during the initial transmural puncture of the fluid collection or during the creation of the fistula tract with electrocautery. ${ }^{12}$ Typically, the perforations are small and can be managed conservatively, especially if carbon dioxide is used for gas insufflation, as opposed to air. ${ }^{13}$ Bleeding can also occur as a complication despite the use of EUS with Doppler to avoid adjacent blood vessels. Puncture site bleeding can occur in patients with collateral vessels secondary to segmental portal hypertension, which can typically be controlled with a large caliber, self-expanding fully covered stent. However, other causes of bleeding can occur from vessels within the collection wall that can bleed after rapid decompression, or secondary to a pseudo-aneurysm, which requires embolization or even surgical exploration. Other complications include stent migration/incorrect deployment, infection of an incompletely drained collection, and, rarely, air embolism or pneumothorax.

\section{ADVANCED THERAPEUTIC EUS TECHNIQUES}

EUS-guided drainage of the biliary and pancreatic ducts has been developed as an alternative for patients who fail conventional drainage. These advanced interventional EUS techniques involve smaller targets, which increases the risk of procedure-related complications.

\section{EUS biliary drainage}

EUS-guided biliary duct drainage has been described for patients who fail conventional endoscopic retrograde cholangiopancreatography (ERCP). The biliary system is accessed either transduodenally (choledocho-duodenostomy) or transgastrically (hepatico-gastrostomy) for direct access or as a rendezvous procedure. EUS-guided biliary drainage is associated with a greater than $90 \%$ technical success rate..$^{14} \mathrm{~A}$ meta-analysis by Khan et al. demonstrated a cumulative adverse event rate following EUS-guided biliary drainage of $17 \%{ }^{15}$ Complication rates also vary according to the different biliary access routes, and choledocho-duodenostomy is associated with a lower stent dysfunction rate, as well as fewer overall complications. ${ }^{15,16}$ Procedure-related complications include bleeding, perforation, cholangitis, and stent migration. Bile leakage is another complication associated with bile tracking along the stent into the peritoneum, but this risk has decreased from $11 \%$ to $4 \%$ after switching from plastic stents to fully covered self-expanding metal stents. ${ }^{16}$

\section{EUS pancreatic duct drainage}

EUS-guided pancreatic duct drainage is one of the most technically challenging EUS interventions and it is associated with a high risk of complication and failure. These procedures are categorized as either EUS-guided rendezvous drainage or pancreatico-gastrostomy. These are the more technically demanding EUS interventions due to smaller targets, the difficulty in maintaining the position along the axis of the main pancreatic duct, inability to dilate the transmural tract due to dense pancreatic fibrosis, and difficulty with advancing the necessary equipment secondary to the acute angle at which the pancreatic duct is often accessed by EUS. ${ }^{2}$ In light of the inherent challenges, the technical success rate has been documented at $89 \%,{ }^{17}$ while the procedural complication rate varies in the literature from $5 \%$ to $43 \%{ }^{2,18-20}$ Immediate complications include bleeding, pancreatitis, development of pancreatic fluid collection/abscess, perforation, and pancreatic duct leakage. ${ }^{17}$

\section{EUS gallbladder drainage}

Traditionally, in patients who are not surgical candidates for cholecystectomy due to underlying medical comorbidities, percutaneous drainage has been considered the drainage option of choice. However, recently, EUS guided drainage has emerged as a safe, efficacious, and minimally invasive option. ${ }^{21,22}$ EUS identifies the gallbladder from either the stomach or duodenum and allows for internal drainage. Reported technical success rates are greater than $90 \%$, which is significantly higher than the $83 \%$ technical success rate of transcystic stenting via ERCP. ${ }^{23}$ EUS gallbladder drainage has also demonstrated similar clinical and technical success rates as compared with percutaneous drainage, but with fewer adverse events. ${ }^{21,23-25}$ Its associated complications are similar to those of EUS biliary duct drainage, including bleeding, infection, perforation, stent migration, bile leakage, etc., with a $10 \%$ adverse event rate. ${ }^{26}$

\section{TRAINING IN INTERVENTIONAL EUS}

The field of interventional EUS is rapidly expanding with the continuous addition of new techniques, including not only the aforementioned procedures, but also other procedures such as celiac plexus block, tumor ablation, EUS-guided 
anastomosis, etc. Though the field of interventional EUS is exciting, a disciplined clinical pathway to the skillful utilization of these techniques is critical. The EUS-guided ERCP consortium meeting of 2011 brought together leading experts to generate recommendations for training in these procedures. Their guidelines highlighted the following categories of endoscopists who may qualify to perform therapeutic EUS techniques: (1) Those who routinely perform pancreaticobiliary EUS and fine needle aspiration (FNA); (2) Those with extensive ERCP and EUS experience for nearly 4-5 years (at least 200-300 EUS and ERCP each year); (3) Those with a 95\%-98\% success rate for standard ERCP with normal anatomy; and (4) Those working in a center with interventional radiology and/or pancreatic-biliary surgery back-up. ${ }^{27}$

After demonstrating adequate experience with the prerequisite skills, a trainee can begin to become adept in therapeutic EUS techniques. Trainees must be mentored by an expert endoscopist to ensure mastery of each step of the technique: needle puncture, tract dilation, and stent placement. ${ }^{28} \mathrm{~A}$ trainee must also experience gradual independence, starting with large endoscopic targets (i.e., pancreatic pseudocysts) and moving to progressively smaller targets (i.e., gallbladder/ biliary/pancreatic drainage). In tandem with the increasing complexity of the types of therapeutic procedures, the risk of potential complications also increases. Therefore, an endoscopist must be comfortable managing potential complications prior to taking on the responsibility of interventional EUS. Although there are no established guidelines to determine competency for these procedures, sufficient training at high-volume centers with structured competency markers is a requirement to perform interventional EUS.

\section{CONCLUSIONS}

With the development of interventional EUS, endoscopists are able to use minimally invasive techniques to manage patients who previously could only be treated via percutaneous drainage by interventional radiologists or via open/laparoscopic resection by surgeons. However, in comparison to diagnostic EUS, interventional EUS does carry a higher risk of complications, particularly in the context of more technically difficult procedures, such as EUS-guided pancreaticobiliary drainage. While complication rates vary based on the type of interventional procedure, all interventional EUS procedures are technically demanding and require the skill of experienced endoscopists. Nevertheless, interventional EUS techniques are very feasible and most have an overall technical success rate of greater than $90 \%$. Despite the lack of established guidelines to determine competency for these procedures, trainees with sufficient clinical experience at high-volume centers can learn to safely perform interventional EUS. The field has advanced rapidly during the past decade with novel devices that facilitate these technically challenging techniques. Continued advancements in endoscopic technology will further enhance these procedures and reduce the rate of adverse events.

\section{Conflicts of Interest}

The authors have no financial conflicts of interest.

\section{REFERENCES}

1. Perez-Miranda M, Barclay RL, Kahaleh M. Endoscopic ultrasonography-guided endoscopic retrograde cholangiopancreatography: endosonographic cholangiopancreatography. Gastrointest Endosc Clin N Am 2012;22:491-509.

2. Lakhtakia S. Complications of diagnostic and therapeutic endoscopic ultrasound. Best Pract Res Clin Gastroenterol 2016;30:807-823.

3. ASGE Training Committee, Jorgensen J, Kubiliun N, et al. Endoscopic retrograde cholangiopancreatography (ERCP): core curriculum. Gastrointest Endosc 2016;83:279-289.

4. Rosenthal LS. Is a fourth year of training necessary to become competent in EUS and ERCP? Notes from the 2008 class of advanced endoscopy fellows. Gastrointest Endosc 2008;68:1150-1152.

5. Varadarajulu S, Bang JY, Sutton BS, Trevino JM, Christein JD, Wilcox CM. Equal efficacy of endoscopic and surgical cystogastrostomy for pancreatic pseudocyst drainage in a randomized trial. Gastroenterology 2013;145:583-590.el.

6. Park DH, Lee SS, Moon SH, et al. Endoscopic ultrasound-guided versus conventional transmural drainage for pancreatic pseudocysts: a prospective randomized trial. Endoscopy 2009;41:842-848.

7. Siddiqui AA, Adler DG, Nieto J, et al. EUS-guided drainage of peripancreatic fluid collections and necrosis by using a novel lumen-apposing stent: a large retrospective, multicenter U.S. experience (with videos). Gastrointest Endosc 2016;83:699-707.

8. Shah RJ, Shah JN, Waxman I, et al. Safety and efficacy of endoscopic ultrasound-guided drainage of pancreatic fluid collections with lumen-apposing covered self-expanding metal stents. Clin Gastroenterol Hepatol 2015;13:747-752.

9. Sadik R, Kalaitzakis E, Thune A, Hansen J, Jonson C. EUS-guided drainage is more successful in pancreatic pseudocysts compared with abscesses. World J Gastroenterol 2011;17:499-505.

10. Kahaleh M, Shami VM, Conaway MR, et al. Endoscopic ultrasound drainage of pancreatic pseudocyst: a prospective comparison with conventional endoscopic drainage. Endoscopy 2006;38:355-359.

11. Varadarajulu S, Bang JY, Phadnis MA, Christein JD, Wilcox CM. Endoscopic transmural drainage of peripancreatic fluid collections: outcomes and predictors of treatment success in 211 consecutive patients. J Gastrointest Surg 2011;15:2080-2088.

12. Vilmann AS, Menachery J, Tang SJ, Srinivasan I, Vilmann P. Endosonography guided management of pancreatic fluid collections. World J Gastroenterol 2015;21:11842-11853.

13. Isayama $\mathrm{H}, \mathrm{Nakai} Y$, Rerknimitr $\mathrm{R}$, et al. Asian consensus statements on endoscopic management of walled-off necrosis part 1: epidemiology, diagnosis, and treatment. J Gastroenterol Hepatol 2016;31:1546-1554.

14. Hara K, Yamao K, Mizuno N, et al. Endoscopic ultrasonography-guided biliary drainage: who, when, which, and how? World J Gastroenterol 2016;22:1297-1303.

15. Khan MA, Akbar A, Baron TH, et al. Endoscopic ultrasound-guided biliary drainage: a systematic review and meta-analysis. Dig Dis Sci 2016;61:684-703. 
16. Kawakubo $\mathrm{K}$, Isayama $\mathrm{H}$, Kato $\mathrm{H}$, et al. Multicenter retrospective study of endoscopic ultrasound-guided biliary drainage for malignant biliary obstruction in Japan. J Hepatobiliary Pancreat Sci 2014;21:328-334.

17. Tyberg A, Sharaiha RZ, Kedia P, et al. EUS-guided pancreatic drainage for pancreatic strictures after failed ERCP: a multicenter international collaborative study. Gastrointest Endosc 2017;85:164-169.

18. Fujii LL, Topazian MD, Abu Dayyeh BK, et al. EUS-guided pancreatic duct intervention: outcomes of a single tertiary-care referral center experience. Gastrointest Endosc 2013;78:854-864.e1.

19. Kahaleh M, Hernandez AJ, Tokar J, Adams RB, Shami VM, Yeaton P. EUS-guided pancreaticogastrostomy: analysis of its efficacy to drain inaccessible pancreatic ducts. Gastrointest Endosc 2007;65:224-230.

20. Alvarez-Sánchez MV, Jenssen C, Faiss S, Napoléon B. Interventional endoscopic ultrasonography: an overview of safety and complications. Surg Endosc 2014;28:712-734.

21. Tyberg A, Saumoy M, Sequeiros EV, et al. EUS-guided versus percutaneous gallbladder drainage: isn't it time to convert? J Clin Gastroenterol 2016 Dec 22 [Epub]. https://doi.org/10.1097/mcg.0000000000000786.

22. Teoh AYB, Serna C, Penas I, et al. Endoscopic ultrasound-guided gallbladder drainage reduces adverse events compared with percutaneous cholecystostomy in patients who are unfit for cholecystectomy. Endos- copy 2017;49:130-138.

23. Khan MA, Atiq O, Kubiliun N, et al. Efficacy and safety of endoscopic gallbladder drainage in acute cholecystitis: is it better than percutaneous gallbladder drainage? Gastrointest Endosc 2017;85:76-87.e3.

24. Anderloni A, Buda A, Vieceli F, Khashab MA, Hassan C, Repici A. Endoscopic ultrasound-guided transmural stenting for gallbladder drainage in high-risk patients with acute cholecystitis: a systematic review and pooled analysis. Surg Endosc 2016;30:5200-5208.

25. Kedia P, Sharaiha RZ, Kumta NA, et al. Endoscopic gallbladder drainage compared with percutaneous drainage. Gastrointest Endosc 2015;82:1031-1036.

26. Dollhopf M, Larghi A, Will U, et al. EUS-guided gallbladder drainage in patients with acute cholecystitis and high surgical risk using an electrocautery-enhanced lumen-apposing metal stent device. Gastrointest Endosc 2017 Mar 1 [Epub]. https://doi.org/10.1016/j.gie.2017.02.027.

27. Kahaleh M, Artifon EL, Perez-Miranda M, et al. Endoscopic ultrasonography guided biliary drainage: summary of consortium meeting, May 7th, 2011, Chicago. World J Gastroenterol 2013;19:1372-1379.

28. Feurer ME, Draganov PV. Training for advanced endoscopic procedures. Best Pract Res Clin Gastroenterol 2016;30:397-408. 